\title{
NOISE MEASUREMENT WITH SMART DEVICE AND EXTERNAL MICROPHONE - BASICS, ACCURACY AND APPLICATIONS
}

\author{
Dobriyan Benov, Diyana Benova
}

\begin{abstract}
The noise level is measured by instruments called noise meters. In this paper, we look at the possibility of using smart devices with an external microphone instead of noise meters. We explore and compare types of smart devices, external microphones, and software. Their accuracy is compared to professional certified tools. The possibilities for their application in different situations are examined and recommendations are made.
\end{abstract}

Keywords: smart device, external microphone, noise measurement

\section{INTRODUCTION}

Nowadays, smart devices are used in every sphere to solve a variety of tasks. Apart from being a means of communication, they have long since taken away the role of amateur (and why not professional) cameras and camcorders. There are pluggable devices for accepting credit card payments, distance measurement, scanning, night vision cameras, and even replacing the traditional multimeter [1].

There is no doubt the convenience of using the pocket smart device with an extra pluggable device that fits in a wallet instead of the suitcases with traditional professional tools. Of course, the advantage is far from being limited to that. As well as shortcomings.

The biggest drawback of using such devices to measure noise is, of course, their accuracy, and whether they meet regulatory requirements for professional use.

\section{REGULATORY}

Professional instruments for measuring noise must meet different international standards, such as the American National Standards Institute (ANSI) S1.4-1983, Specifications for Sound Level Meters and International Electrotechnical Commission (IEC) 61672-1 [2]. Such standards define multiple acoustic and electrical tests with specified tolerances and measurement uncertainties that are defined in decibels over a wide frequency range (usually from $10 \mathrm{~Hz}$ to $20 \mathrm{kHz}$ ).

The tests should take into account level linearity, directionality, time and frequency-weightning responses, tonebursts, radio frequency interference, and atmospheric and environmental conditions. The standards also specify that these tests are performed on the complete instrument, including the microphone and the preamplifier.

To date, no smart device app meets the requirements of either IEC or ANSI standards. However, we will take a look at experimental research conducted by several research groups to find out if the smart device, software, and external microphone configuration can be used to correctly measure the noise level.

\section{TECHNICAL DATA}

Kardous and Shaw [3] are studying 192 iOS and Android platforms for noise measurement [4].

Of these, they only approve 4 iOS apps. In general, none of the Android-based apps meet the initial testing criteria, mainly because the Android market is fragmented among many manufacturers with different parts requirements and lack of equal audio integration of software and hardware across devices [5]. The digital circuits and computing capabilities of the smartphone far exceed the power, speed and storage capacity of any professional tool on the market today.

However, the built-in MEMS microphone remains a major weakness. Progress in MEMS microphone design and technology shows that these microphones now compete with the best power and condenser microphones used in current sound meters in terms of frequency response, power requirements and environmental/electromagnetic specifications. The MEMS microphone continues to have some limitations due to its small size and layout, which affects its dynamic range and signal-to-noise ratio [6]. Another significant constraint of embedded microphones is the lack of accessibility and the inability to perform periodic or pre-measurement. Several apps feature a feature that allows users to attach an external microphone to the iOS headphone jack. Several external "audio measurement" microphones are commercially available, using four sockets, a configuration Tip-Ring1-Ring2-Sleeve (TRRS) For use with most earphone jacks. Two external microphones with similar specifications, a cheap Dayton Audio iMM-6 microphone (Springboro, $\mathrm{OH}$ ) and the more expensive MicW i436 (Beijing, China) were selected for this study, which the manufacturer reported to be in compliance with IEC 61672- 1 Class 2 specification. Both microphones use electret-condenser capsules and 
are non-directional. The main reason for choosing the two microphones is their wide commercial availability and size (ability to fit into a typical acoustic adapter for calibrators). Table 1 provides an overview of the main features of the microphone. Table 1. Specifications of the i436 and iMM-6 external microphones.
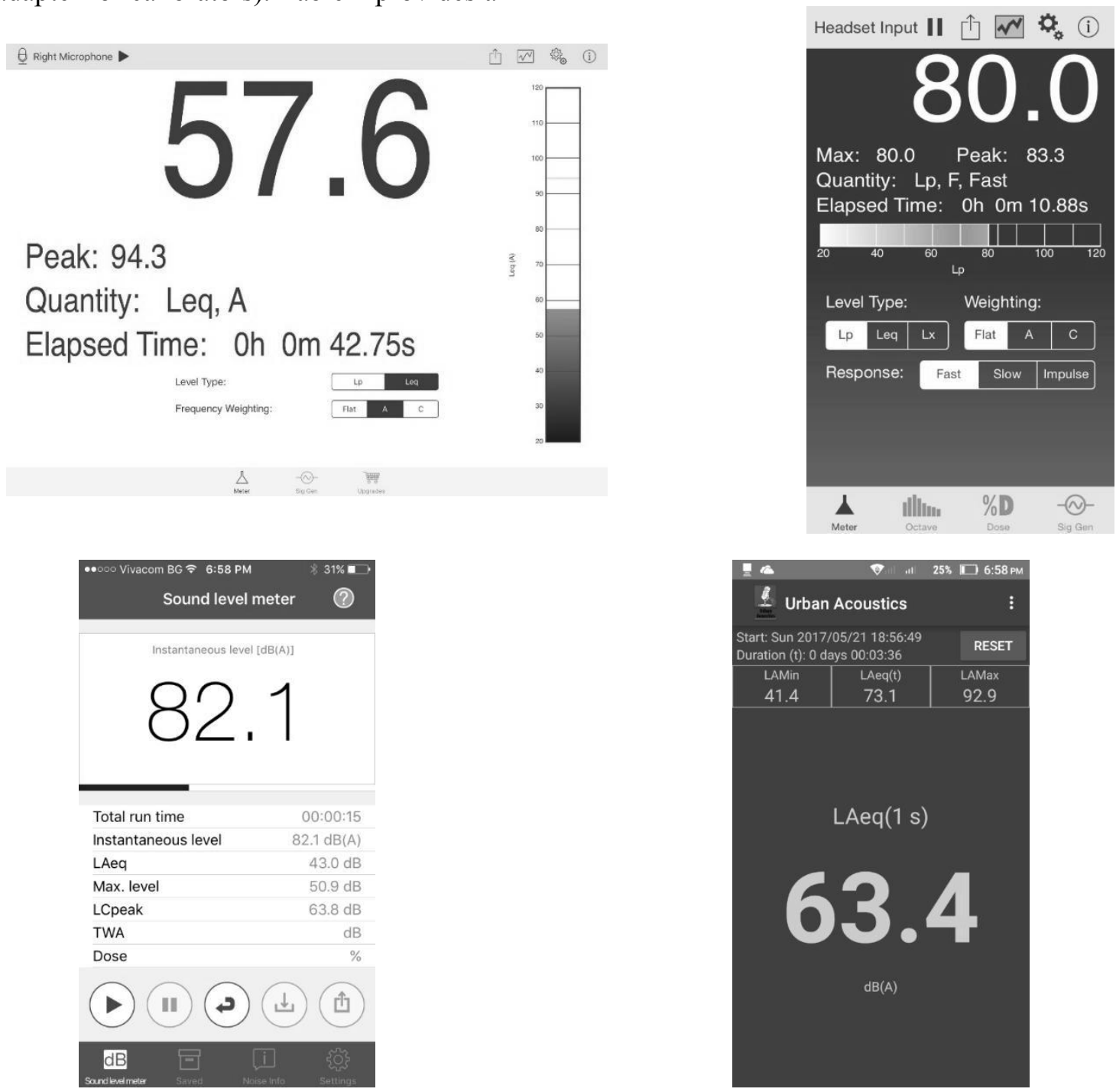

Fig. 1. Faber Acoustical SoundMeter 8.4.3 (iOS - iPad Mini 4, iPhone 5), NIOSH 1.0.4.34 (iOS, iPhone 5), Benovi Engineering Urban Acoustics 1.0.1 (Android, Lenovo K10)

Table 1. Overview of the main features of the microphones

\begin{tabular}{|c|c|c|c|c|c|c|}
\hline Microphone & Cost & $\begin{array}{c}\text { Capsule } \\
\text { size }\end{array}$ & Sensitivity & $\begin{array}{c}\text { Freq. } \\
\text { response }\end{array}$ & S/N ratio & $\begin{array}{c}\text { Max. } \\
\text { SPL }\end{array}$ \\
\hline $\mathrm{i} 436$ & $\$ 150$ & $7 \mathrm{~mm}$ & $6.3 \mathrm{mV} / \mathrm{Pa}$ & $20 \mathrm{~Hz}-20 \mathrm{kHz}$ & $>62 \mathrm{~dB}$ & $128 \mathrm{~dB}$ \\
\hline $\mathrm{iMM}-6$ & $\$ 15$ & $6 \mathrm{~mm}$ & $10 \mathrm{mV} / \mathrm{Pa}$ & $18 \mathrm{~Hz}-20 \mathrm{kHz}$ & $70 \mathrm{~dB}$ & $127 \mathrm{~dB}$ \\
\hline
\end{tabular}

\section{EXPERIMENTAL STUDY}

The experiment of Murphy and King [7] is realized by broadband white noise in a reverberation camera. The reference noise is generated by the Brüel \& Kjær's Pulse Measurement System, version 18.1, and broadcast by the Type 4292-L OmniPower dodecahedron loudspeaker located in the center of the room. The output is set to broadcast a uniform sound field at $50 \mathrm{~dB}(\mathrm{~A}), 70 \mathrm{~dB}(\mathrm{~A})$, and then 90 $\mathrm{dB}(\mathrm{A})$. These values were initially confirmed using both a rotating microphone boom fitted with a diffuse field microphone as well as a calibrated Brüel \& Kjær 
Type 2250 SLM. Background noise was measured on each test day and was found to be $27 \mathrm{~dB}(\mathrm{~A})$ in the reverberation room. Testing was conducted over 10 separate days. As an experimental precaution, the room was tested immediately before and after each testing schedule to ensure that the room acoustics remained consistent across testing schedules. Unlike other studies that tests smartphones for weighted and unweighted sound levels, Murphy and King [7] focusses only on the ability of phones to measure A-weighted sound level used espessialy for measuring environmental noise.

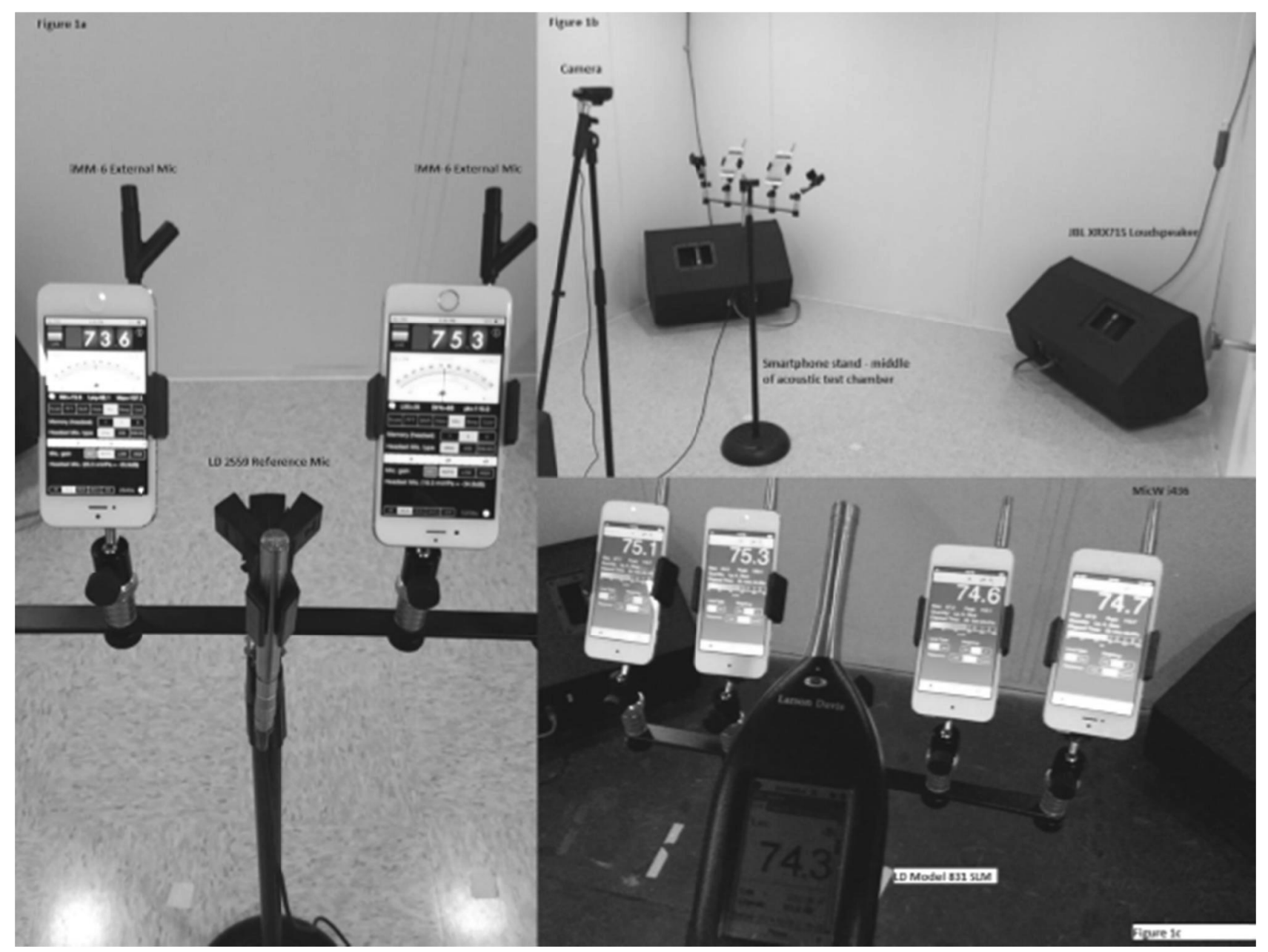

Fig. 2. (a) SPLnFFT app using iMM-6 microphones compared to $1 / 2$ in. Larson-Davis 2559 random incidence type 1 microphone (left), (b) test setup at NIOSH acoustic test chamber (top right), and (c) SoundMeter app using 1436 microphones and Larson-Davis SLM 83 (bottom right).

Kardous and Shaw [2] generates pink noise with a $20 \mathrm{~Hz}-20 \mathrm{kHz}$ frequency range, at levels from 65 to 95 $\mathrm{dB}$ in 5-dB increments (7 different noise levels). They examined the accuracy of the unweighted (or flat) sound levels for each device over the 65-95 dB SPL test range. The measurement range was chosen to reflect the majority of typical occupational noise exposures encountered in the workplace today. The measurements were conducted in a diffuse sound field at a reverberant chamber at the NIOSH Acoustic Testing Laboratory. The diffuse sound field ensured that the location, orientation, and size of the microphones did not influence the results of the study. Noise generation and acquisition are performed using the Trident software (ViAcoustics, Austin, TX). Noise is generated through three JBL XRX715 two-way loudspeakers oriented to provide maximum sound diffusivity inside the chamber. Reference sound level measurements is obtained using a 1/2-inch Larson-Davis (DePew, NY) model 2559 random incidence microphone. In addition, a LarsonDavis model 831 type 1 SLM is used as a secondary reference, mostly for confirmation of the laboratorybased system and verification of the overall results. Both the reference system and the SLM are considered to be 
type 1/class 1 devices as indicated in ANSI S1.4 and IEC-61672-1 standards. The microphone and SLM are calibrated before and after each measurement using the Larson-Davis model CAL250 precision acoustic calibrator. All the reference measurement instrumentation used in the study underwent annual calibration at a National Institute of Standards and Technology accredited laboratory. Smartphones are set up on a stand in the middle of the chamber at a height of approximately $4 \mathrm{ft}$ to mimic the height of a person conducting a smartphone-based noise measurement. Fig. 2 shows the test setup inside the reverberant chamber and arrangements of the speakers and smartphones. The study was conducted using 4 apps (SoundMeter, SPLnFFT, SPL Pro, and NoiSee), 7 nominal sound levels $(65,70,75,80,85,90$, and $95 \mathrm{~dB})$, and 6 blocks. A total of 6 different iPhones (3 iPhone 5S's and 3 iPhone 6's) and 6 different sets of iMM-6 and i436 external microphones were used.

\section{RESULTS}

The results of testing the fixed effects of the smartphone apps showed that there was no evidence of differences between apps, both for the iMM- 6 and for the 1436 microphones [2]. Also, there was no evidence that the measurements of the four apps differed from those made by the reference system; the least squares means of differences did not differ significantly from zero, as indicated by the fact that all of the $95 \%$ confidence intervals for the estimates contained zero (see Table 2). In testing the fixed effects of nominal sound levels, there were two main findings: (1) there was no evidence that the measured differences depended on the nominal sound level for both the iMM-6 and for the i436 microphones, and (2) there was no evidence of an interaction between nominal sound levels and apps. Tukey-adjusted multiple comparisons of the apps were performed, and as expected, there were no differences overall due to "app".

Table 2. Least squares means of difference by microphone and app

\begin{tabular}{|c|c|c|c|c|c|}
\hline Microphone & Application & Estimate & Std. error & Pr $>|\mathbf{t}|(\mathbf{p}$-value) & 95\% confidence interval \\
\hline iMM6 & NoiSee & 0.1976 & 0.1780 & 0.3072 & $(-0.2323,0.6276)$ \\
\hline iMM6 & SPL Pro & 0.06905 & 0.1780 & 0.7108 & $(-0.3609,0.4990)$ \\
\hline iMM6 & SPLnFFT & 0.1190 & 0.1780 & 0.5272 & $(-0.3109,0.5490)$ \\
\hline iMM6 & SoundMeter & 0.08571 & 0.1780 & 0.6463 & $(-0.3442,0.5157)$ \\
\hline \hline i436 & NoiSee & -0.1095 & 0.1087 & 0.3386 & $(-0.3534,0.1343)$ \\
\hline i436 & SPL Pro & -0.1262 & 0.1087 & 0.2740 & $(-0.3700,0.1176)$ \\
\hline i436 & SPLnFFT & -0.1833 & 0.1087 & 0.1241 & $(-0.4272,0.06050)$ \\
\hline i436 & SoundMeter & -0.2333 & 0.1087 & 0.0587 & $(-0.4772,0.01050)$ \\
\hline
\end{tabular}

Fig. 3 shows box plots of the differences between the reference system and the app measurements for the four apps (SoundMeter, SPLnFFT, SPL Pro, and NoiSee) over the seven nominal sound levels for both the iMM- 6 and i436 external microphones.

The results show that the differences in measurements between the reference system and each of the SoundMeter and SPL Pro apps were mostly between $61 \mathrm{~dB}$ for all sound levels for both the iMM-6 and i436 microphones while the SPLnFFT and NoiSee apps appeared to have slightly wider variations for the iMM-6 microphones at the 65-75 dB sound levels.

Fig. 4 shows box plots of the differences between the reference system and app measurements by app and by nominal sound level for both the iMM-6 and 1436 microphones. Visual inspection of the graphs suggests that the medians of the differences for the iMM-6 microphones were slightly higher than those for the i436 microphones.

Fig. 5 shows box plots of the differences between the reference system and app measurements by app and by sound level for the internal versus the external microphones. Data from the internal microphones were gathered from the previous study.

The results show that the use of external and calibrated microphones improved the accuracy and precision of the measurements, the mean difference obtained using the external microphones, $0.023 \pm 0.530$ [mean 6 standard deviation], was considerably less than that obtained for internal microphones, $1.646 \pm 3.795$, as was the range for external microphones, $(-1.4,1.8)$ [min, max], compared to that for the internal microphones, $(-14,11.3)$. 


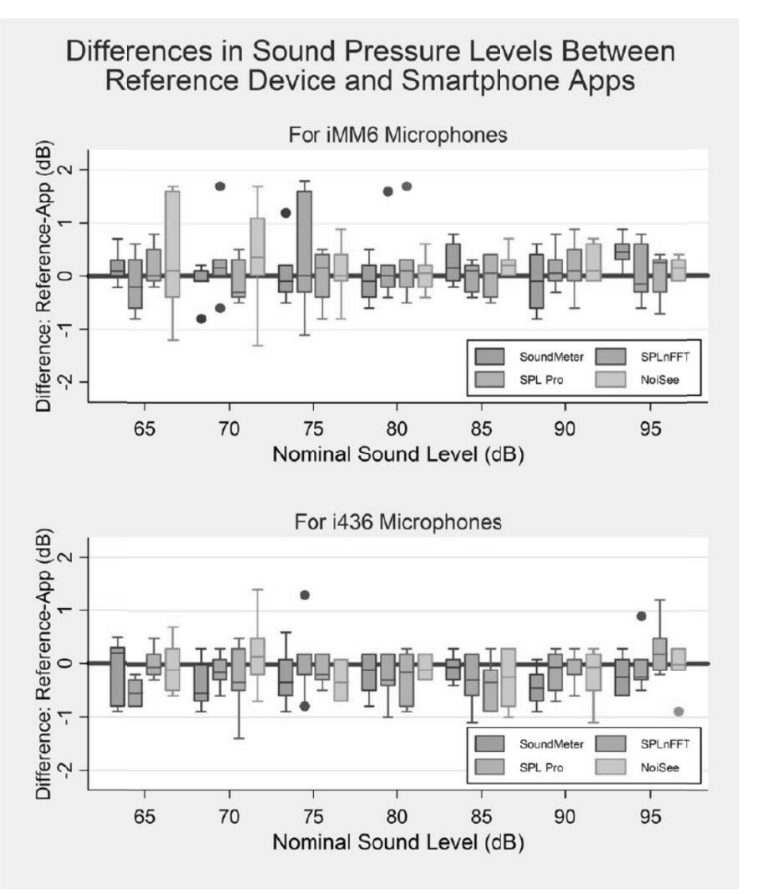

Fig. 3. (a) Box plots of differences [difference (SPL)jreference output-app output) between measurements by the reference system and by smartphone apps by nominal sound levels for iMM-6 microphones (top), and (b) box plots of differences for i436 microphones (bottom).

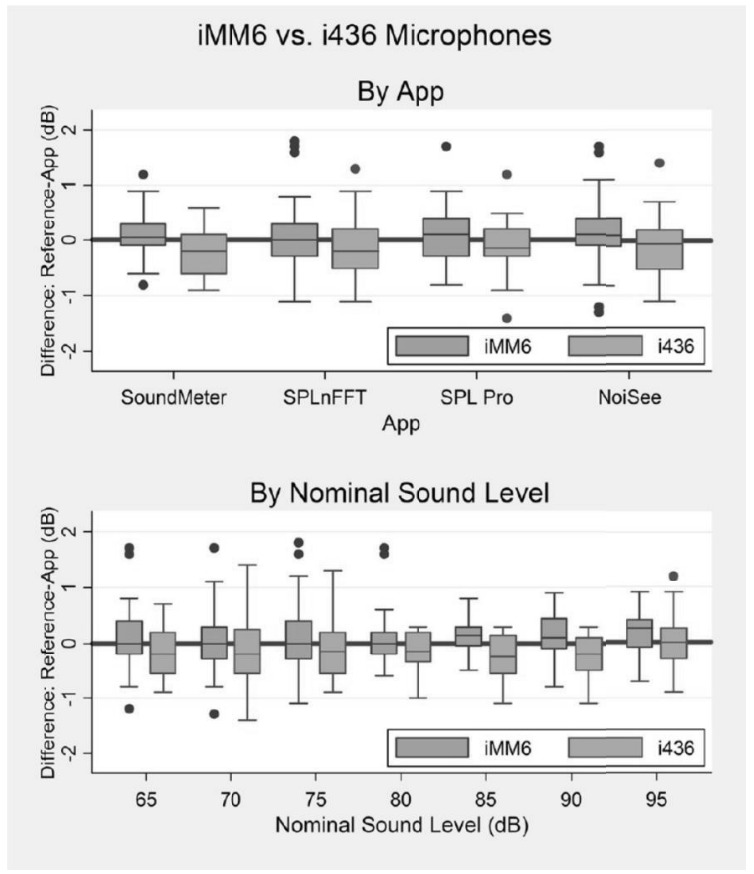

Fig. 4. (a) Box plots of the differences between the reference and app measurements for both iMM-6 and i436 microphones by app (top), and (b) by nominal sound levels (bottom).

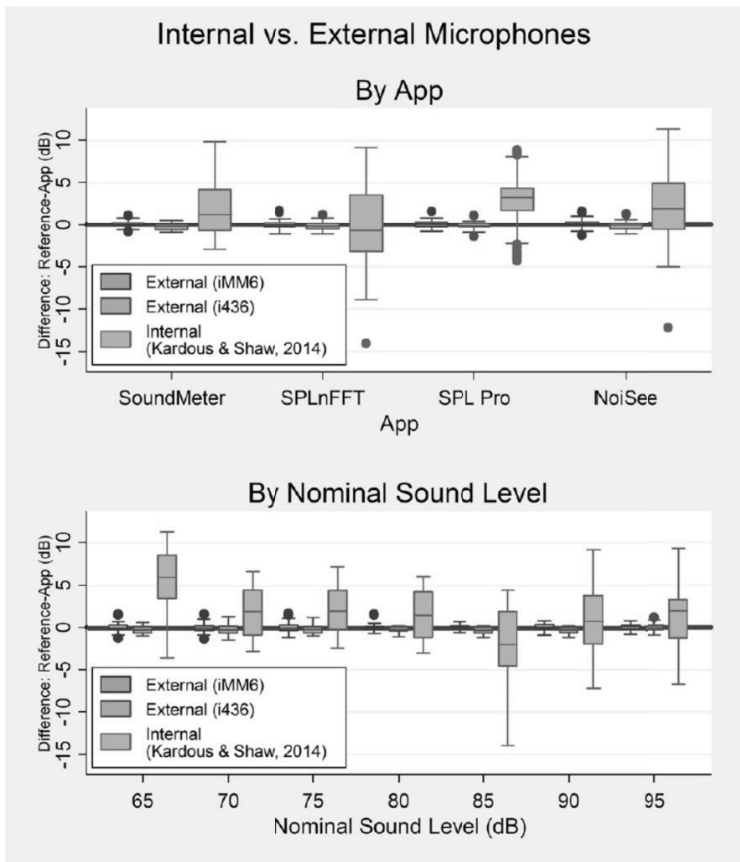

Fig. 5. (a) Box plots of differences between the reference and app measurements for internal and external microphones by app (top), and (b) by nominal sound levels. Data for the internal microphones were gathered in our previous study [8] (bottom). 


\section{APPLICATION}

As was mentioned at the outset, as the configuration considered does not meet international standards, it can not be applied to official environmental noise damages. In the US, however, technology is used to measure workplace noise.

Environmentally sound noise masters can use the manual manual method because the accuracy of smart devices that work with the iOS platform

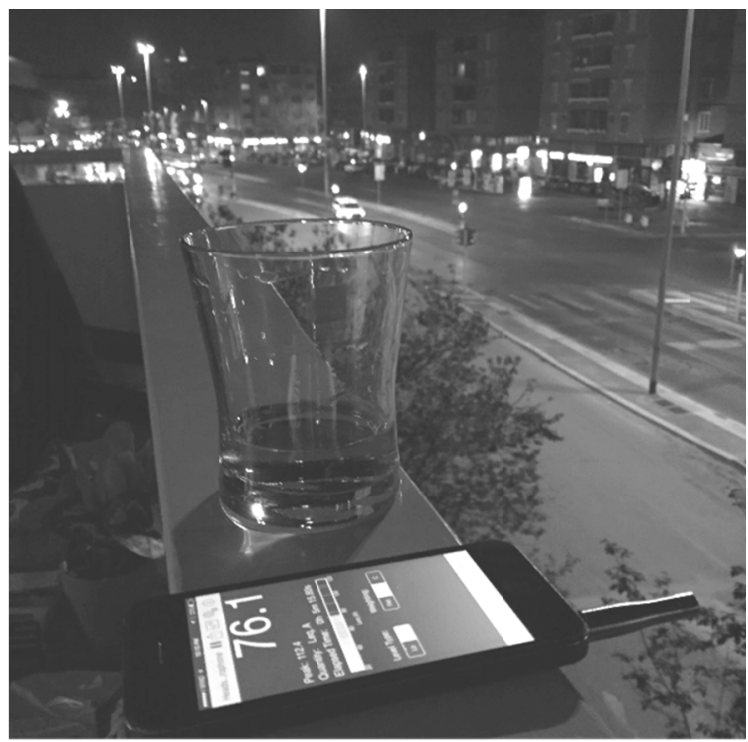

and an external microphone give accurate results.

In Figure 6 are shown examples of noise measurement on the terrace of a hotel on Via Gregorio VII, Rome, Italy (left), and the noise of the railroad traffic on the railroad overpass at Kovachevo stop on the Septemvri-Plovdiv railway section - part of the TransEuropean railway network, Septemvri - Pazardzhik interchange (right). In both cases, we use the Wi436 microphone with devices based on the iOS platform.

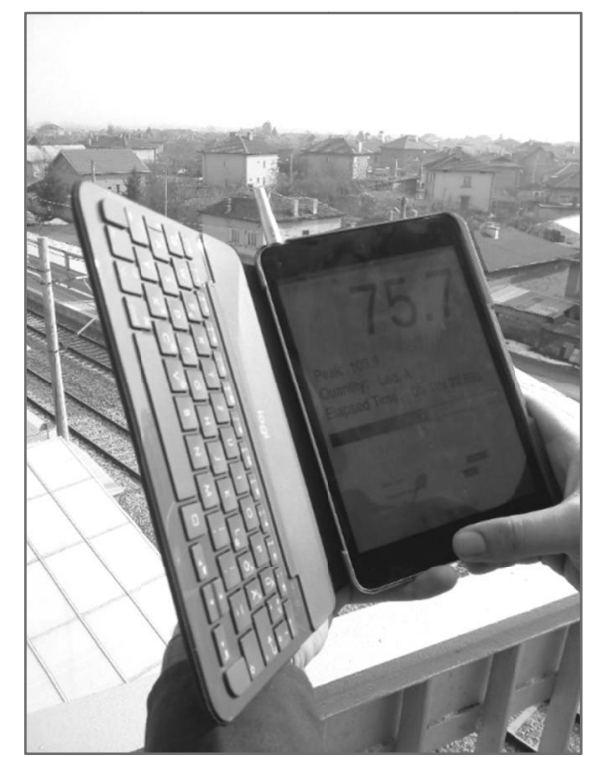

Fig. 6. Via Gregorio VII, Rome, Italy (left), railroad overpass at Kovachevo stop on the Septemvri-Plovdiv railway section - part of the Trans-European railway network, Septemvri - Pazardzhik interchange (right).

Of course, the purpose of this study is to show measurement accuracy with a smart device and an external microphone. Experts and others who deal with noise could be equipped with sufficiently precise equipment at a considerably lower price than professional tools and explore environmental noise for different purposes.

\section{FURTHER WORK}

Since the configuration described has the required features, it has to go in the direction of standardization of smart devices, software and microphones so that professional tools can be integrated with the pocket technology that each of us owns. Undoubtedly the benefits are many.

An interesting idea is creating a community noise map that is updated by enthusiasts. Something like a social network of noise experts $[9,10]$. Many problems have to be solved for the realization of such an idea, but the first steps have already been taken. Zuo, Xia [11] offer a noise-mapping method based on smartphones to effectively and easily measure environmental noise. By using this method, a noise map of an entire area can be created using limited measurement data. They believe that the proposed noise-mapping method is a feasible and low-cost noise-mapping solution.

In the same direction they work Murphy and King [12]. Their report is about a research undertaken to assess the possibility for smartphone-based noise mapping data to be integrated into the traditional strategic noise mapping process. They compare maps generated using the traditional approach with those generated using smartphone-lbased measurement data. The advantage of the latter approach is that it has the potential to remove the need for exhaustive input data into the source calculation model for noise prediction. In addition, the study also tests the accuracy of smartphone-based measurements against simultaneous measurements taken using traditional sound level meters in the field.

Also interesting would be a mobile application which calculates the approximate dimensions of a noise screen or its effectiveness, taking into account 
the noise level of the existing transport artery whose level is measured by the method described.

We hope that this review will give direction and ideas for the development of the idea in the future, in particular in Bulgaria

\section{REFERENCES}

1. Benov, D., Use of a mobile phone as a computer (surveying applies), in 16th International Symposium on "Modern Technologies, Education and Professional Practice in Geodesy and Related Fields". 2006: Sofia, Bulgaria. p. 51.

2. Kardous, C.A. and P.B. Shaw, Evaluation of smartphone sound measurement applications (apps) using external microphones-A follow-up study. The Journal of the Acoustical Society of America, 2016. 140(4): p. EL327-EL333.

3. Kardous, C.A. and P.B. Shaw, So How Accurate Are These Smartphone Sound Measurement Apps?, in NIOSH Science Blog. 2014.

4. Staab, W., Smartphone Sound Level Meter Apps - Part II. Hearing Health \& Technology Matters, 2015.

5. Roberts, B., C. Kardous, and R. Neitzel, Improving the accuracy of smart devices to measure noise exposure. Journal of Occupational and Environmental Hygiene, 2016. 13 (11): p. 840-846.

6. Robinson, D. and J. Tingay, Comparative study of the performance of smartphone-based sound level meter apps, with and without the application of a 1/2" IEC-61094-4 working standard microphone, to IEC-61672 standard metering equipment in the detection of various problematic workplace noise environments, in Inter-noise 2014. 2014: Melbourne, Australia.

7. Murphy, E. and E. King, Testing the accuracy of smartphones and sound level meter applications for measuring environmental noise. Applied Acoustics, 2016. 106: p. 16-22.

8. Kardous, C.A. and P.B. Shaw, Evaluation of smartphone sound measurement applications. The Journal of the Acoustical Society of America, 2014. 135(4): p. EL186-EL192.

9. Qin, Z. and Z. Yanmin, NoiseSense: A Crowd Sensing System for Urban Noise Mapping Service in 2016 IEEE 22nd International Conference on Parallel and Distributed Systems (ICPADS). 2016: Wuhan, China.

10. Maisonneuve, N., et al., NoiseTube: Measuring and mapping noise pollution with mobile phones, in 4th International ICSC Symposium. 2009, Springer Berlin Heidelberg: Thessaloniki, Greece. p. 215-228.

11. Zuo, J., et al., Mapping Urban Environmental Noise Using Smartphones. Sensors (Basel, Switzerland), 2016. 16(10): p. 1692.

12. Murphy, E. and E. King, Smartphone-based noise mapping: Integrating sound level meter app data into the strategic noise mapping process. Science of The Total Environment, 2016. 562: p. 852-859.

13. Shim, E., et al., Designing a Sustainable Noise Mapping System Based on Citizen Scientists Smartphone Sensor Data. PLOS ONE, 2016.

\section{ИЗМЕРВАНЕ НА НИВОТО НА ШУМА СЬС СМАРТ-УСТРОЙСТВО И ВЬНШЕН МИКРОФОН - ОСНОВИ, ТОЧНОСТ И ПРИЛОЖЕНИЕ}

Добриян Бенов, Дияна Бенова

Резюме: Нивото на шума се измерва чрез инструменти, наречени шумомери. В настояшия материал разглеждаме възможността за използване на смарт-устройства с външен микрофон вместо шумомери. Изследваме и сравняваме видовете смарт-устройства, външни микрофони и софтуер. Съпоставяме тяхната точност с тази на професионални сертифицирани инструменти. Разглеждаме възможностите за приложението им в различни ситуации и са направени препоръки.

Ключови думи: смарт устройство, външен микрофон, измерване на шума

\section{Dobriyan Benov \\ Diyana Benova}

Benovi Engineering Ltd., 81V Bulgaria Blvd., 1404 Sofia, Bulgaria

phone: 0878358647

e-mail: benova@benov.org

\section{Добриян Бенов \\ Дияна Бенова}

Бенови Инженеринг ЕООД, 1404 София, бул. България 81В

телефон: 087835864752

e-mail: benova@benov.org 